\title{
Albright Hereditary Osteodystrophy without Multiple Hormone Resistance
}

National Cancer Institute

\section{Source}

National Cancer Institute. Albright Hereditary Osteodystrophy without Multiple Hormone

Resistance. NCI Thesaurus. Code C129722.

A condition caused by inactivating mutation(s) in the paternal allele of the GNAS gene, encoding Gs-alpha, resulting in expression of the Gs-alpha protein from only the maternal allele. Affected individuals have the clinical phenotype of Albright hereditary osteodystrophy without hormone resistance. 